\title{
O PORTFÓLIO COMO ESTRATÉGIA DE APRENDIZAGEM E PRÁTICA PROFISSIONAL NAS LICENCIATURAS EM EAD
}

\author{
CURITIBA /PR MAIO/2018
}

\author{
Maristela Reis Sathler Gripp - UNINTER - maristelarsg@yahoo.com.br \\ Paula Cristina Reis Oliveira - UNINTER - maristelarsg@yahoo.com.br \\ Deisily Quadros - UNINTER - maristelarsg@yahoo.com.br \\ Dinamara Machado - UNINTER - maristelarsg@yahoo.com.be
}

\author{
Tipo: Relato de Experiência Inovadora (EI) \\ Categoria: Conteúdos e Habilidades \\ Setor Educacional: EDUCAÇÃO SUPERIOR
}

\begin{abstract}
RESUMO
Uma das dificuldades dos cursos de licenciatura a distância tem sido conciliar a teoria aprendida às práticas necessárias para a formação do futuro professor. Foi nesse contexto que a UNINTER adotou em todos os seus cursos de licenciatura a prática do portfólio como uma maneira de possibilitar ao futuro docente, momentos em que a teoria aprendida seria aliada à prática, possibilitando uma aplicação mais eficiente dos conteúdos abordados pelas aulas. Dessa forma, o portfólio foi incluído em todas as fases dos cursos de licenciatura, a partir de temas da atualidade relacionados à educação. Desde a sua implementação até hoje, temos observado o aprimoramento do formato dos portfólios e percebido que isso tem contribuído muito na formação dos nossos alunos e proporcionado um envolvimento dos polos também. Diante disso, acreditamos que o portfólio é uma prática que pode propiciar uma atuação efetiva do nosso aluno tanto na sua formação profissional, como na mobilização dos polos de ensino.
\end{abstract}

Palavras-chave: portfólio- educação- prática - docente 


\section{INTRODUÇÃO}

De acordo com Torres (2008), os alunos que procuram os cursos de licenciaturas serão os futuros educadores e, portanto, necessitam de uma sólida formação cultural e humanística, a fim de que atuem com êxito no campo da Educação. O magistério exige uma renovação constante de conhecimentos e de práticas, além de exigir um grande comprometimento dos seus profissionais. Sendo assim, Torres (2008) afirma que é de suma importância refletir sobre a formação dos futuros profissionais de educação, em especial de Letras, e como podemos prepará-los para avaliar seus alunos, desenvolver postura crítica e auto-avaliação. Segundo a autora, é a partir dessa constatação que o portfólio surge como uma possibilidade de prática que abrange os objetivos de uma educação de qualidade.

A prática do portfólio auxilia tanto na formação do aluno quanto na área profissional da Educação.

A palavra portfólio tem origem no italiano portafolglio que significa "recipiente onde se guarda folhas soltas". O uso dessa expressão começou a ser utilizado no ambiente das artes, porque os artistas costumavam guardar seus trabalhos em grandes pastas de papel para preservá-los. Na área educacional, o conceito de portfólio mudou. Ele tem sido usado como uma forma de prática e avaliação profissional que faz parte da formação do aprendiz. Atualmente, já é possível encontrarmos autores que utilizam o termo "webfólio" que agrega o uso da tecnologia à elaboração do portfólio eletrônico.

O portfólio tem sido usado como um procedimento de avaliação justamente pela sua capacidade de aliar o currículo e as práticas pedagógicas. Algumas instituições de ensino já adotam um "teaching portfolio", ou seja, um portfólio da prática pedagógica dos candidatos à carreira docente (Torres, 2008, p. 551). Além disso, a partir do portfólio é possível observar o desenvolvimento processual do aluno, não se limitando a aplicação de provas e testes.

Embora apresente vantagens e desvantagens, adotar a prática do portfólio dos cursos de graduação tem trazido mais benefícios do que prejuízos. Um dos aspectos positivos a respeito do portfólio é que ele permite uma organização do próprio aluno a partir das suas experiências e dos conteúdos trabalhados durante o curso. Isso é uma grande vantagem no processo de formação desse aluno, uma vez que todos os alunos são beneficiados com esse tipo de procedimento e não apenas aqueles que normalmente se destacariam em atividades como elaborar uma apresentação oral e escrita como resultado de suas pesquisas. Além disso, de acordo com Vilas Boas (2004) o portfólio, é 
o tipo de atividade que possibilita ao aluno descobrir as suas potencialidades e talentos, favorecendo o diálogo entre os interlocutores envolvidos.

Apesar das vantagens descritas até aqui, o portfólio também pode trazer algumas desvantagens ao processo de aprendizagem. Geralmente, a maioria dos alunos que chega a graduação hoje são oriundos de um sistema educacional que não privilegia a independência, nem a autonomia, muito menos a criatividade, por isso, num primeiro momento, esses alunos podem se sentir desconfortáveis para executar uma atividade que não possui um padrão pré-estabelecido, ou seja, eles deverão construir o caminho para chegarem aos resultados pretendidos. Uma outra dificuldade é o fato do portfólio, às vezes, ser confundido com uma "coleção de trabalhos" o que obriga uma boa preparação do tutor na condução das propostas e do processo. Entretanto, o que se deseja ao final da elaboração do portfólio é que os alunos se tornem responsáveis pelo seu processo de aprendizagem e que adquiram mais autonomia diante do processo de aprendizagem.

\section{A implementação do processo}

O portfólio foi implantado na Escola Superior de Educação/ESE -UNINTER em 2016. A Escola oferece vários cursos de licenciatura, dentre eles o curso de Letras que é o nosso foco nesse trabalho. Nessa ocasião, os professores e coordenadores dos cursos de licenciaturas, perceberam que a prática do portfólio poderia possibilitar uma formação mais eficiente dos futuros docentes. Com esse objetivo, foi criado o NPESE - Núcleo de Práticas da Escola Superior de Educação a fim de estabelecer as normas para elaboração do trabalho, bem como encaminhar as propostas de intervenção que seriam repassadas a cada fase aos alunos. Ficou estabelecido que o objetivo do portfólio seria entrelaçar ainda mais a teoria com a prática, a partir das vivências do cotidiano, juntamente com a resolução de problemas. Essas atividades visam a um trabalho interdisciplinar, não tendo um vínculo direto com as disciplinas das Unidades Temáticas de Aprendizagem.

O manual do portfólio desenvolvido pelo NPESE - Núcleo de Práticas da Escola Superior de Educação estabeleceu como portfólio como um projeto integrador que deve ser desenvolvimento com o apoio dos polos, conforme orientação que segue:

\footnotetext{
“Portfólio - essa avaliação consiste de um projeto integrador construído pelos alunos sob orientação do tutor do polo. A proposta é determinada pela Coordenação do Curso e acompanhada pelo tutor do polo, responsável por delinear os objetivos e estrutura do projeto a ser desenvolvido pelos alunos, buscando a interdisciplinaridade e articulação teórico-prática dos conteúdos estudados nas unidades curriculares. (NPESE, 2016, p. 1).
} 
De acordo com as normas do NEPSE, o objetivo do portfólio é o desenvolvimento de atividades que reúnam a prática e a teoria, aprimorando a formação dos alunos dos cursos de licenciatura:

O objetivo do Portfólio é o desenvolvimento de atividades que promovam a práxis com qualidade acadêmica nos polos de apoio presencial, a elevação dos índices de aceitação da modalidade de EaD em território nacional, a promoção de ações de inserção e reconhecimento do mercado de trabalho e a formação humana e acadêmica ( NPESE-UNINTER, 2016, p. 6).

As atividades elaboradas no portfólio deverão ser estabelecidas pela coordenação do curso de acordo com o projeto político pedagógico do curso:

O Portfólio é uma atividade pedagógica que consiste no conjunto de trabalhos realizados pelos acadêmicos durante determinado período - uma fase - e com premissas estabelecidas anteriormente pela coordenação do curso, de acordo com o projeto político pedagógico. (NPESE-UNINTER, 2016, p. 4).

Os temas a serem abordados nos trabalhos para os cursos de licenciaturas obedecem aos eixos de interesse como descritos no Manual do portfólio que é encaminhado aos alunos via ambiente virtual:

EIXO 1 - Tecnologia e inovação

EIXO 2 - Modalidades de ensino: a educação especial e inclusiva

EIXO 3 - Contexto e diferentes contextos na educação

EIXO 4 - Lúdico: brinquedos, jogos, brincadeiras e dinâmicas como estratégias de ensino-aprendizagem ( NPESE-UNINTER, 2016, p. 10).

O objetivo é que os eixos contemplem diferentes linguagens e auxiliem no aperfeiçoamento do uso da norma padrão:

\footnotetext{
"As atividades propostas em cada um desses eixos abordarão as diferentes linguagens, a formação científica e cultural, a pesquisa, o aperfeiçoamento do uso da língua portuguesa e a intervenção na realidade/sociedade. Para isso, serão propostas de modo que propiciem a leitura, a escrita, a oralidade, o desenvolvimento e a aplicação da teoria em práticas, bem como a pesquisa. As práticas poderão resultar em seminários interdisciplinares, oficinas para a comunidade, laboratórios, projetos, e-books, vídeos, fotografias, dentre outros modos de socializar as descobertas". (NPESE, 2016, p. 4)
}

Além disso, as atividades priorizam a interdisciplinariedade utilizando temas que permitam o acesso às diferentes áreas de pesquisa em linguagens, sendo assim, "uma tentativa de aproximar a teoria e a prática, num processo de construção de 
aprendizagem e de avaliação formativa, processual e diagnóstica" (NP, 2016, p. 4).

\begin{abstract}
O planejamento das atividades propostas segue uma organização que visa a construção de competências que contemplem a escrita de diferentes gêneros e variadas práticas como estabelece o manual: "As atividades propostas estão organizadas em três etapas para as licenciaturas e quatro etapas para os
bacharelados, que buscam a construção de competências a partir da teoria e da prática. Essas etapas
contemplam:

$1^{\text {a }}$ etapa: leitura e pesquisa (por meio de diferentes linguagens, o aluno conhece mais sobre o tema discutido)

$2^{\text {a }}$ etapa: prática (o aluno experiência, vivencia uma determinada situação prática)

$3^{\text {a }}$ etapa: escrita (o aluno produz diferentes gêneros textuais tendo como base a leituras e pesquisas realizadas e seu conhecimento prévio.

4⿳亠丷厂 - etapa: apresentação no polo (o aluno compartilha os resultados de sua pesquisa com colegas e com a comunidade) $\mathrm{E}$, ao final de cada documento, há os anexos e templates/modelos, que auxiliarão o aluno na resolução das atividades propostas (NPESE-UNINTER, 2016, p. 7).
\end{abstract}

Nesses dois anos de implantação, o portfólio tem demonstrado uma aceitação e enriquecimento das práticas que vem sendo desenvolvidas, como podemos verificar nos dados coletados pela equipe do NPESE:

- 2017: 6 momentos de formação com corretores;

- 2017/18: 11 portfólios produzidos;

- 2017: 6 polos visitados;

- 2017: 272.273 postagens e correções

- Abril/2018: 537 solicitações respondidas.

\title{
Considerações Finais
}

Num pais em que professores e alunos estão relegados ao segundo plano, estudar é mais do que nunca uma necessidade. É fundamental nos preocuparmos com a formação dos futuros docentes, se queremos ver o nosso país sair do patamar de ignorância e miséria em que tem vivido até hoje. Nesse sentido, uma formação que privilegie a autonomia e a pesquisa dos futuros docentes é da maior relevância. Os cursos de Licenciatura vêm sofrendo um verdadeiro êxodo! A maioria dos jovens acaba optando por profissões mais respeitadas e rendosas socialmente. Por isso, adotar práticas que possam melhorar a formação que hoje é dada ao docente deve ser a prioridade dos cursos de formação de professores. Como profissional responsável pela formação de outros profissionais, o professor deve ser capaz de ter uma visão crítica que os ajude a construir um ensino da língua que seja eficiente e que não se baseie apenas em cópia do que já existe. 
Diante disso, adotar o portfólio como uma prática /que venha a favorecer o estudo e a autonomia dos alunos, irão contribuir para uma postura diferenciada na prática profissional desses alunos. Nesse sentido, o portfólio pode contribuir para atenuar as muitas lacunas de formação trazidas por esses alunos dos segmentos anteriores, ajudando-os a identificarem os problemas de aprendizagem atuais. Além disso, segundo Torres (2008) a prática do portfólio proporcionar uma abordagem processual da aprendizagem, fazendo com que os alunos das licenciaturas pratiquem o ensino de uma forma mais significativa para eles e para a comunidade escolar envolvida nesse processo.

Referências bibliográficas:

TORRES, S. C. G. Portfólio como instrumento de aprendizagem e suas implicações para a prática pedagógica reflexiva. Ver. Diálogo Educ, Curitiba, v. 8, n. 24, p. 549-561, maio/ago. 2008.

VILLAS BOAS, B. M. F. Portfólio, avaliação e trabalho pedagógico. Campinas, SP: papiros, 2004.

Ambiente Virtual/ AVA

MANUAL DO PORTFÓLIO, Núcleo de Práticas da Escola Superior de Educação, ESSE/UNINTER, p. 1 -3 